\title{
Safety and Efficacy of Endoscopic Treatment of Solitary Gastric Neurofibroma
}

\author{
Meihong $\mathrm{Yu}^{1,2}$ \\ Kaixuan $\mathrm{Li}^{3}$ \\ Deliang Liu ${ }^{1,2}$ \\ Yuyong Tan ${ }^{1,2}$
}

'Department of Gastroenterology, The Second Xiangya Hospital of Central South University, Changsha, Hunan, People's Republic of China; ${ }^{2}$ Research Center of Digestive Disease, Central South University, Changsha, Hunan, People's Republic of China; ${ }^{3}$ Department of Urology, Xiangya Hospital of Central South University, Changsha, Hunan, People's Republic of China
Correspondence: Yuyong Tan Department of Gastroenterology, The Second Xiangya Hospital of Central South University, No. 139 Middle Renmin Road, Changsha, Hunan, 4I00II, People's

Republic of China

Tel +86- I5 I I628062I

Fax +86-73I-85533525

Email tanyuyong@csu.edu.cn

Kaixuan $\mathrm{Li}$

Department of Urology, Xiangya Hospital of Central South University, No. 87

Xiangya Road, Changsha, Hunan, 410008,

People's Republic of China

Tel +86-I5580027242

Email lkxxgz@csu.edu.cn
Purpose: The studies on solitary gastric neurofibroma (GN) consist of only individual case reports, with little data and relevant information. We aimed to summarize the clinical features, endoscopic features, imaging findings, and pathological features and study the safety and efficacy of endoscopic treatment of solitary GN.

Patients and Methods: We retrospectively collected and analyzed clinical data of patients who underwent endoscopic treatment in Department of Gastroenterology of a well-known tertiary hospital from August 2007 to September 2019 and were accurately diagnosed as having solitary GN.

Results: A total of 788 patients with gastric submucosal tumors underwent endoscopic treatment, among whom 11 patients were found to have solitary GNs. The incidence of solitary GNs was 1.4\%. All 11 patients were treated with endoscopy. Five patients underwent endoscopic full-thickness resection (EFTR) and six patients underwent endoscopic submucosal excavation (ESE). The en bloc resection rate of the 11 lesions was $100.0 \%$. The median endoscopic operation time was 80 minutes. Average length of hospital stay was $6.4 \pm 1.6$ days. The median follow-up time was 29 months. No recurrence, distant metastasis, or disease-related death occurred during the follow-up.

Conclusion: EFTR and ESE can serve as feasible, safe, and effective treatments for solitary GN.

Keywords: endoscopic full-thickness resection, endoscopic submucosal excavation, gastric, neurofibroma, solitary

\section{Introduction}

Neurofibroma is a rare benign peripheral nerve sheath tumor, often derived from the abnormal proliferation of nerve sheath cells. ${ }^{1,2}$ It can be divided into solitary neurofibroma and neurofibromatosis (NF) according to it is single, multiple or accompanied by other systemic diseases. Solitary neurofibroma is a local single tumor without other manifestations of NF, often presenting different clinical manifestations because of its occurrence in different locations. ${ }^{3}$ To date, solitary neurofibroma has been reported in the oral cavity, ${ }^{4}$ mandible, ${ }^{5}$ parotid gland, ${ }^{6}$ penis, ${ }^{7}$ spermatic cord,${ }^{8}$ infratemporal fossa, ${ }^{9}$ abdominal wall, ${ }^{10}$ gallbladder, ${ }^{11}$ bile duct, ${ }^{12}$ esophagus, ${ }^{13}$ colon, ${ }^{14}$ etc. However, the studies on solitary gastric neurofibroma (GN) consist only individual case reports, with little data and little usable information.

Solitary GN is a benign protuberant lesion usually originating from the submucosa. Its preoperative diagnosis is difficult, and it requires intraoperative or postoperative pathological examination for an accurate diagnosis. ${ }^{3,8}$ Surgery has been the preferred 
treatment for GN in the past. With the rapid development of endoscopic diagnosis and treatment technology, endoscopic submucosal dissection (ESD), endoscopic submucosal excavation (ESE), endoscopic full-thickness resection (EFTR), and submucosal tunneling endoscopic resection (STER) are increasingly being used for removing gastrointestinal submucosal tumors. Endoscopic treatment like EFTR, ESE have been widely used because they have less invasion, shorter resection time, fewer adverse events and lower cost compared with surgical operation. ${ }^{15-19}$

In the present study, we retrospectively analyzed the clinical data of 11 cases of solitary GNs, aiming to summarize the clinical features, endoscopic features, imaging findings, and pathological features and to explore the safety and efficacy of endoscopic treatment.

\section{Materials and Methods}

\section{Patients}

The subjects of this study were patients with solitary GN diagnosed by pathological examination after endoscopic treatment in the Department of Gastroenterology in a well-known tertiary hospital, from August 2007 to September 2019. The inclusion criteria were as follows: (I) White light endoscopy, endoscopic ultrasonography (EUS) and computerized tomography (CT) confirmation that the bulge was located in the stomach, not elsewhere, and no high risk of malignancy (such as irregular borders, cyst lesions, internal heterogeneity, etc.) or signs of metastasis or invasion outside the gastrointestinal tract were noticed; (II) The bulge was solitary; (III) The gastric submucosal bulge was removed by endoscopic treatment including ESD/ESE/ EFTR/STER; (IV) Pathological examination after endoscopic treatment confirmed gastric neurofibroma; (V) The clinical data of the patient was complete. Finally, of 788 cases of gastric submucosal tumors treated by endoscopy, 11 cases were GNs (Figure 1). The 11 consecutive patients were enrolled and their clinical data, endoscopic data, imaging findings, pathological features, treatment methods and effects, postoperative complications, and data on follow-up recurrence and metastasis were collected.

The study was approved by the institutional ethics committee (No. 2020K014) and all patients were informed of the potential benefits and risks before endoscopic surgery and then signed informed consent. All procedures followed were in accordance with the ethical standards of the responsible committee on human experimentation (institutional and national) and with the Helsinki Declaration of 1975 .

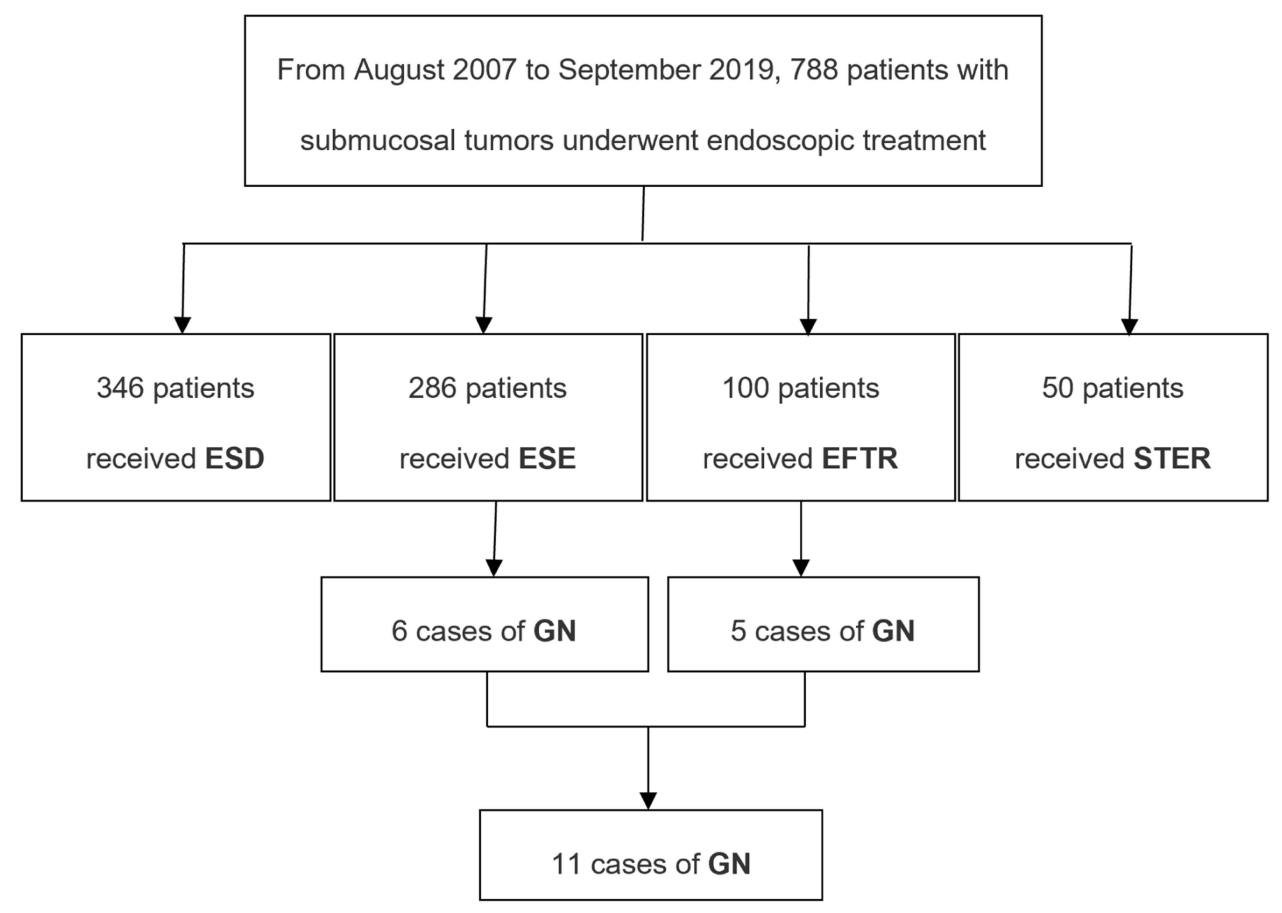

Figure I Flowchart of patient selection.

Abbreviations: ESD, endoscopic submucosal dissection; ESE, endoscopic submucosal excavation; EFTR, endoscopic full-thickness resection; STER, submucosal tunneling endoscopic resection; GN, gastric neurofibroma. 


\section{Endoscopic Therapy \\ Endoscopic Treatment-Related Equipment}

Gastroscopy (GIF Q260J, Olympus); EUS (EU-ME1/A75, Olympus); Dual knife (KD-650Q); Insulation-tip knife (KD-611L, Olympus); Hook knife (KD-620L, Olympus); Transparent cap (D-201-11802, Olympus); Argon plasma coagulation unit (APC300; ERBE); High-frequency generator (ICC 200/300, Olympus); Injection needle (NM-4L1, Olympus); Hemostatic clips (HX-600-90); etc.

\section{ESE and EFTR Procedures}

Whether patients underwent ESE or EFTR surgery was mainly determined by the origin layer and growth pattern of the submucosal tumor. Submucosal tumors with mainly out-growth pattern, or originating from the serosal layer or deep muscularis layer which adhere with the serosal layer were treated with EFTR, others were treated with ESE. All the ESE and EFTR procedures were carried out by experienced operators who had performed more than 100 gastric ESE/EFTR operations before treating the first patient in the present study. EUS guided fine needle aspirations (FNA) was not performed before endoscopic excision. R0 resection was considered as primary endpoint. All patients were fasted 8 hours before the operations. Six patients underwent ESE procedures and five patients underwent EFTR procedures. All procedures were completed under general anesthesia. The ESE procedure (Figure 2) and EFTR procedure (Figure 3) were performed as previously reported. ${ }^{20-22}$

\section{Postoperative Management and Follow-Up Strategy}

The resected specimens were subjected to hematoxylineosin (H\&E) staining and immunohistochemical (IHC) staining. The postoperative management was performed as previously reported. ${ }^{20-22}$ Patients were fasted for 3-5 days and gradually transitioned to a normal diet in two weeks, all of whom intravenous proton-pump inhibitor (PPI) and antibiotics were used for 3 days. Patients need to review gastroscopy at the 3th, 6th, 12th months after the ESE/EFTR for the first year, and then once a year. If necessary, EUS, abdominal CT, or biopsy could be performed on residual and recurrent lesions. Each patient was followed up for more than 15 months.

\section{Definitions}

Lesion resection was defined in two ways: (I) Successful resection, indicating that lesions were removed without changing the initial treatment plan; and (II) En bloc resection, meaning that on the basis of successful resection, the lesion was completely resected without block resection, and the capsule of the resected specimen was intact without rupture. The duration of ESE/EFTR referred to the time from submucosal injection to completion of wound treatment after lesion removal. Post-EFTR/ESE delayed bleeding occurrence was defined as having any two of the following: (I) hematemesis, melena or dizziness, (II) hemoglobin loss

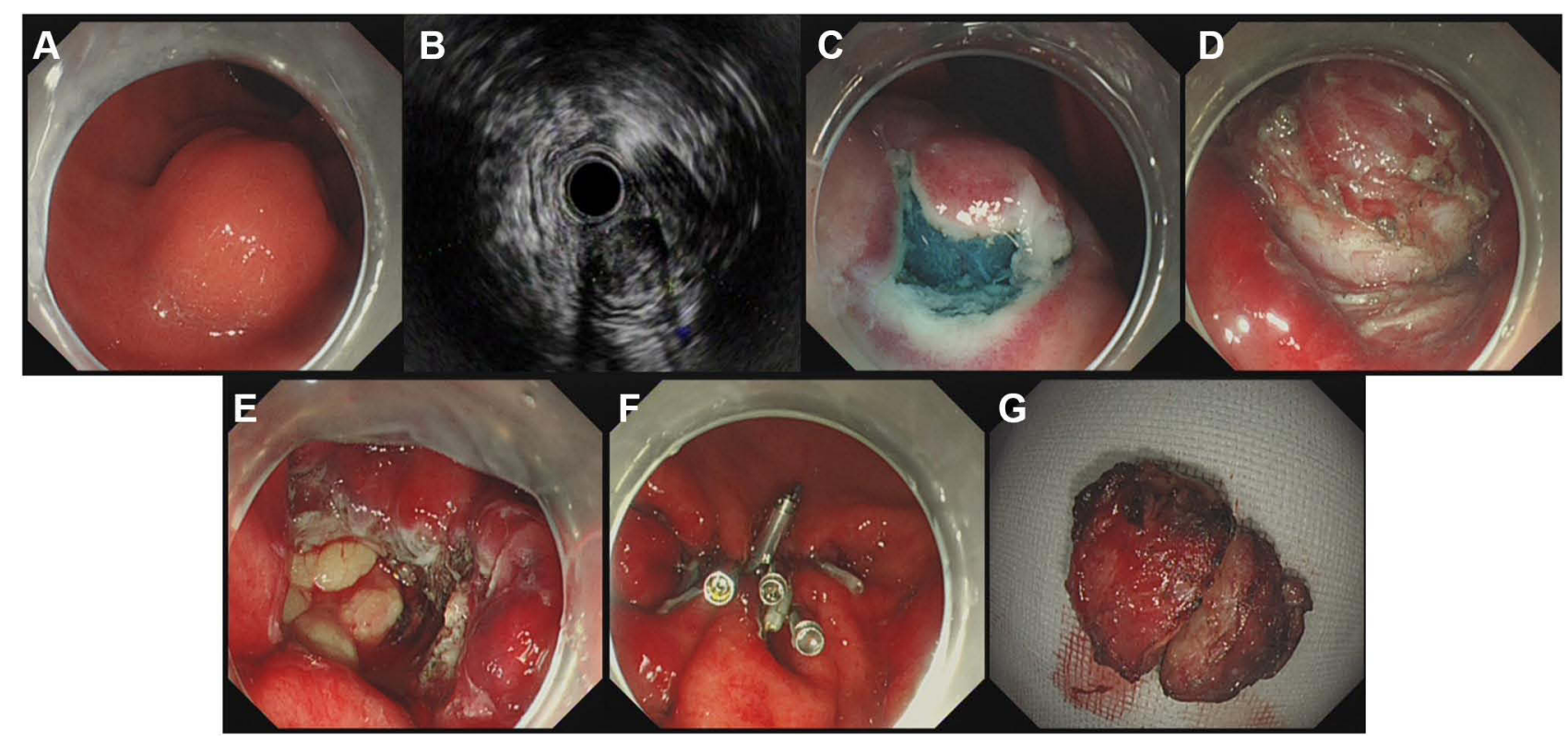

Figure 2 ESE treatment of solitary gastric neurofibroma. (A) Submucosal bulge of posterior gastric fundus; (B) EUS showed that the solitary GN was hypoechoic; (C) incision and stripping of tumor mucosa; (D) exposing and excavating lesions; (E) ESE wound after tumor excavation; (F) metal clip to close the wound; (G) excavated tumor specimen. 


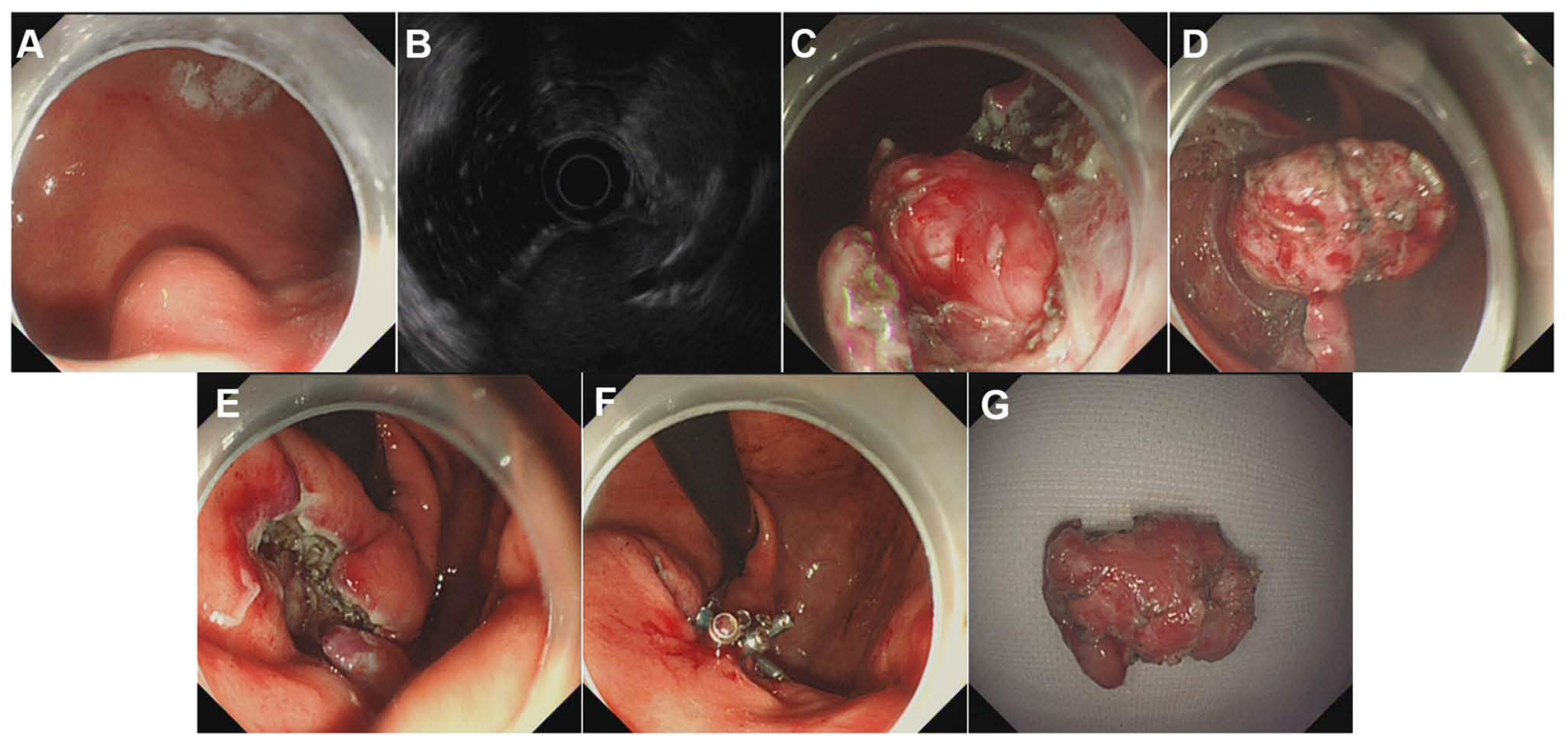

Figure 3 EFTR treatment of solitary gastric neurofibroma. (A) Submucosal bulge of large curvature in lower gastric body; (B) EUS showed that the solitary GN was hypoechoic; (C) incision of tumor mucosa; (D) stripping and resecting of lesions; (E) EFTR wound after tumor resection; (F) metal clip to close the wound; (G) resected tumor specimen.

$>2 \mathrm{~g} / \mathrm{dl}$, (III) blood pressure decrease $>20 \mathrm{mmHg}$ or pulse rate increase $>20 / \mathrm{min}$ and (IV) Forrest I or IIa-IIb on follow-up endoscopy. ${ }^{23}$ Postoperative delayed bleeding (PDB) detected during the endoscopy within 24 hours was classified as early PDB, whereas that detected after 24 hours was classified as late PDB. ${ }^{24}$ Postoperative infection was thought to be the onset of fever $\left(>37.8^{\circ} \mathrm{C}\right)$, abdominal pain, nausea, vomiting, increased white blood cell count $\left(\geq 10.8 \times 10^{9} / \mathrm{L}\right)$ immediately after ESE/EFTR, and perforation was ruled out by abdominal X-ray or CT examination. Peritonitis, abdominal abscess, and abdominal infection were all manifestations of postoperative infection. Delayed perforation was characterized by presence of endoscopically visible pericolic fat or exposure of other intra-abdominal structures through a tear in the muscularis propria or when visible of free or retroperitoneal air shadows on postoperative radiographs. Intraoperative or post-operative surgical conversion occurred when patients who were originally intended to undergo ESE/EFTR were transferred to surgery because of the risk of major adverse events or the difficulty of the original procedure.

\section{Statistical Analysis}

SPSS 21.0 software was used for data analysis. Some results are presented as percentage, median, and range because of the small sample size.

\section{Results}

\section{Baseline Characteristics}

A total of 788 patients with gastric submucosal tumors underwent endoscopic treatment in the Department of Gastroenterology in a well-known tertiary hospital from August 2007 to September 2019. Among them, 11 patients were diagnosed with GN, and the incidence was $1.4 \%$. Table 1 shows the characteristics of the 11 patients, of whom two were male and nine were female. The average age of patients was $54.3 \pm 8.7$ years old. Of the 11 patients, one had a family history of NF, and four had histories of digestive system diseases (two cases of non-atrophic gastritis, one case of reflux esophagitis, and one case of gastric varices). The clinical manifestations in the 11 patients were abdominal pain (54.5\%), abdominal distension (18.2\%), acid regurgitation and heartburn (9.1\%), and asymptomatic (18.2\%).

\section{Endoscopic Features}

Most solitary GNs occurred in the lower part of the gastric body $(54.5 \%)$ and the middle part of the gastric body $(27.3 \%)$, and the greater curvature of the lower gastric body was the most common location (36.4\%). The 11 lesions were protuberant with a smooth surface and no ulceration under white light endoscopy. The average diameter of GNs was $1.9 \pm 0.7 \mathrm{~cm}$. EUS showed that ten 
Table I Clinical Features of the II Solitary GN Patients

\begin{tabular}{|c|c|c|c|c|c|c|c|c|c|c|c|c|c|c|c|c|c|c|}
\hline $\begin{array}{l}\text { Case } \\
\text { No. }\end{array}$ & Age & Gender & Symptoms & $\begin{array}{l}\text { Family } \\
\text { History } \\
\text { of NF }\end{array}$ & $\begin{array}{l}\text { History of } \\
\text { Digestive } \\
\text { Diseases }\end{array}$ & $\begin{array}{l}\text { Origin of } \\
\text { GN }\end{array}$ & $\begin{array}{l}\text { Location } \\
\text { of } \mathrm{GN}\end{array}$ & $\begin{array}{l}\text { Diameter } \\
\text { of GN } \\
(\mathrm{cm})\end{array}$ & $\begin{array}{l}\text { Regular } \\
\text { Shape } \\
\text { of GN }\end{array}$ & $\begin{array}{l}\text { Grow } \\
\text { Pattern of } \\
\text { GN }\end{array}$ & $\begin{array}{l}\text { Resection } \\
\text { Method }\end{array}$ & $\begin{array}{l}\text { Procedure } \\
\text { Time } \\
\text { (mins) }\end{array}$ & $\begin{array}{l}\text { Hospitalization } \\
\text { Time (Days) }\end{array}$ & $\begin{array}{l}\text { Adverse } \\
\text { Events }\end{array}$ & $\begin{array}{l}\text { Microscopic } \\
\text { Characteristics }\end{array}$ & 5100 & CDII7 & $\begin{array}{l}\text { Duration } \\
\text { of Follow- } \\
\text { Up } \\
\text { (Months) }\end{array}$ \\
\hline 1 & 55 & Female & $\begin{array}{l}\text { Abdominal } \\
\text { pain }\end{array}$ & No & Yes & MP & GC-LGD & 1.5 & Yes & Intraluminal & EFTR & 78 & 4 & No & Spindle cells & $\mathrm{P}$ & $\mathrm{N}$ & 58 \\
\hline 2 & 60 & Female & $\begin{array}{l}\text { Abdominal } \\
\text { pain }\end{array}$ & No & No & MP & AW-MGD & 1.0 & Yes & Bidirectional & EFTR & 110 & 9 & No & Spindle cells & $P$ & $\mathrm{~N}$ & 44 \\
\hline 3 & 59 & Male & Asymptomatic & Yes & Yes & MP & GC-LGD & 2.0 & Yes & Bidirectional & EFTR & 80 & 5 & No & Spindle cells & $\mathrm{P}$ & $\mathrm{N}$ & 24 \\
\hline 4 & 53 & Female & $\begin{array}{l}\text { Acid } \\
\text { regurgitation } \\
\text { and heartburn }\end{array}$ & No & No & MP & GC-LGD & 1.2 & Yes & Bidirectional & EFTR & 105 & 8 & No & Spindle cells & $\mathrm{P}$ & $\mathrm{N}$ & 62 \\
\hline 5 & 62 & Female & $\begin{array}{l}\text { Abdominal } \\
\text { pain }\end{array}$ & No & Yes & MP & PW-MGD & 2.0 & Yes & Intraluminal & EFTR & 120 & 7 & No & Spindle cells & $P$ & $\mathrm{~N}$ & 19 \\
\hline 6 & 55 & Female & $\begin{array}{l}\text { Abdominal } \\
\text { distension }\end{array}$ & No & Yes & MP & GC-LGD & 2.0 & Yes & Intraluminal & ESE & 77 & 5 & No & Spindle cells & $\mathrm{P}$ & $\mathrm{N}$ & 15 \\
\hline 7 & 63 & Female & $\begin{array}{l}\text { Abdominal } \\
\text { pain }\end{array}$ & No & No & MP & AW-GN & 3.5 & No & Bidirectional & ESE & 170 & 7 & No & Spindle cells & $\mathrm{P}$ & N & 87 \\
\hline 8 & 59 & Female & $\begin{array}{l}\text { Abdominal } \\
\text { pain }\end{array}$ & No & No & Submucosa & PD-LGD & 1.5 & Yes & Intraluminal & ESE & 14 & 7 & No & Spindle cells & $\mathrm{P}$ & $\mathrm{N}$ & 21 \\
\hline 9 & 40 & Male & Asymptomatic & No & Yes & MP & AW-LGD & 1.5 & Yes & Intraluminal & ESE & 53 & 8 & No & Spindle cells & $P$ & N & 29 \\
\hline 10 & 55 & Female & $\begin{array}{l}\text { Abdominal } \\
\text { pain }\end{array}$ & No & No & MP & AW-MGD & 1.5 & Yes & Intraluminal & ESE & 30 & 5 & No & Spindle cells & $\mathrm{P}$ & $\mathrm{N}$ & 31 \\
\hline 11 & 36 & Female & $\begin{array}{l}\text { Abdominal } \\
\text { distension }\end{array}$ & No & No & MP & PW-GF & 2.8 & Yes & Bidirectional & ESE & 165 & 5 & No & Spindle cells & $\mathrm{P}$ & $\mathrm{N}$ & 25 \\
\hline
\end{tabular}

Abbreviations: GN, gastric neurofibroma; NF, neurofibromatosis; MP, muscularis propria; GC-LGD, greater curvature of lower gastric body; AW-MGD, anterior wall of middle gastric body; PW-MGD, posterior wall of middle gastric body; AW-GN, anterior wall of gastric antrum; PD-LGD, posterior wall of lower gastric body; AW-LGD, anterior wall of lower gastric body; PW-GF, posterior wall of gastric fundus; EFTR, endoscopic full-thickness resection; ESE, endoscopic submucosal excavation; $P$, positive; $N$, negative. 
lesions $(90.9 \%)$ originated from the gastric muscular layer, and one $(9.1 \%)$ originated from the submucosa. All lesions were hypoechoic; ten lesions (90.9\%) had a homogeneous echo, smooth margin and clear boundary, and one $(9.1 \%)$ had multiple small circular echoless structures with unclear boundaries. In addition, six lesions $(54.5 \%)$ protruded into the gastric lumen, and five lesions (45.5\%) protruded both into and out of the gastric lumen.

\section{Imaging Characteristics}

All patients underwent abdominal CT examination, including plain and enhanced scans, before endoscopic therapy. These GNs showed round, oval, or spindle-shaped soft tissue shadows in the gastric wall, with equal or slightly low uniform density, clear boundaries, no obvious adhesion to surrounding tissues, and no invasion of adjacent organ (Figure 4).

\section{Pathological Characteristics}

All lesions were examined histopathologically and with IHC staining. Histological examination demonstrated the tumor cells in the 11 cases were spindle-shaped and most likely arose from mesenchymal tissue. No signs of atypia or significant mitotic activity were observed (Figure 5A). Immunohistochemical analysis showed that tumor cells of the 11 lesions were positive for S-100 protein (Figure 5B) but negative for CD117. And CD34, smooth-muscle actin (SMA), discovered on gastrointestinal stromal tumor (GIST) -1, neuron-specific enolase (NSE), vimentin (Vim) and desmin (Des) showed focal positive and negative results, with focal positive rates of $16.7 \%, 36.4 \%, 9.1 \%, 45.5 \% 45.5 \%$, and $12.0 \%$, respectively. SOX-10 protein was positive in one case (Figure 5C). Ki-67 protein in all specimens ranged from $0 \%$ to $6.0 \%$.

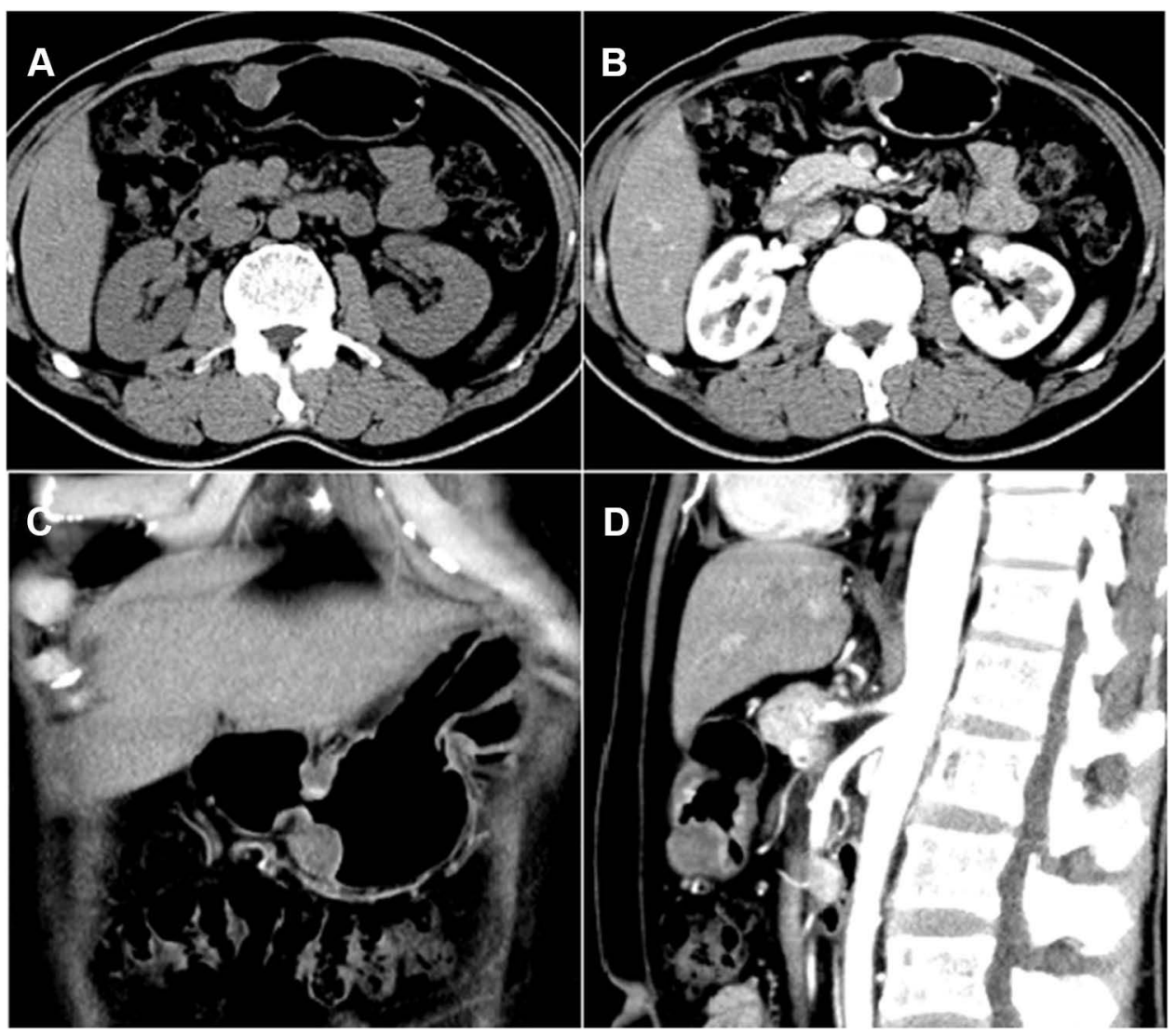

Figure 4 Solitary gastric neurofibroma with a diameter of $2.0 \mathrm{~cm}$ on CT examination. (A) Plain CT showed a soft tissue mass-like lesion in the greater curvature of the stomach in horizontal plane; (B) post-contrast abdominal CT shows the same area not representing the contrast-enhanced appearance in horizontal plane; (C) CT showed a soft tissue mass-like lesion in the greater curvature of the stomach in coronal plane; (D) post-contrast abdominal CT shows the same area not representing the contrastenhanced appearance in sagittal plane. 


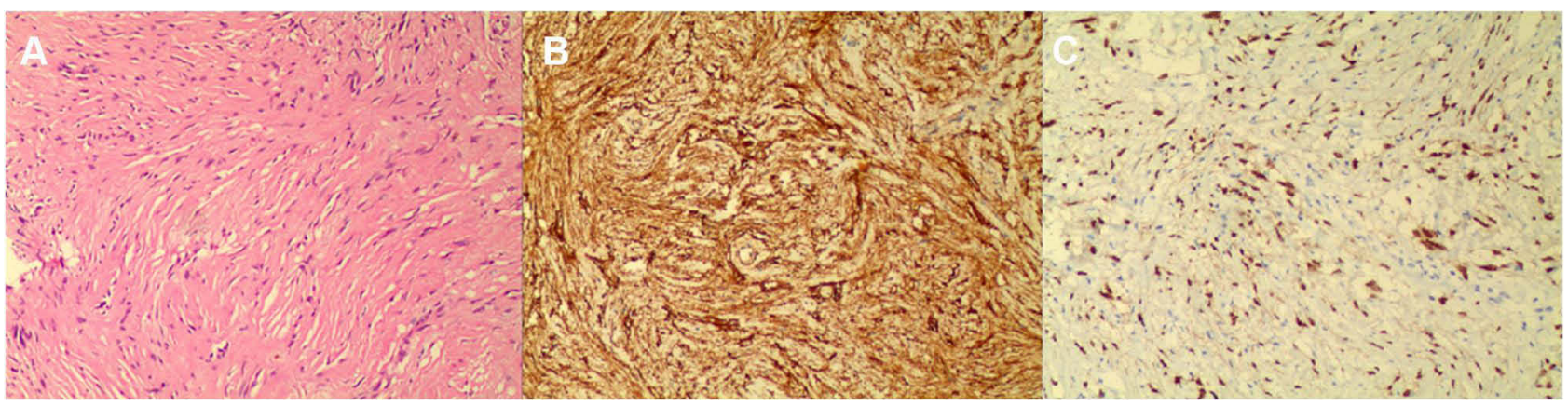

Figure 5 Histological examination of solitary gastric neurofibroma. (A) Histological examination shows spindle-shaped cells with elongated nuclei (H\&E staining, I00X); (B) positive S-100 protein (IHC staining, 100X); (C) positive SOX-10 protein (Immunohistochemical staining, 100X).

\section{Endoscopic Therapy and Follow-Up Assessment}

All 11 patients underwent endoscopic resection, which was successful in all cases. Five patients were treated with the EFTR procedures and six with the ESE. En bloc resection was successful in all patients. The median endoscopic operation time was 80 minutes (14-175 minutes). No intraoperative bleeding or PDB occurred in any patients. They were hospitalized for 4-9 days, with an average length of stay of $6.4 \pm 1.6$ days. In the present study, the median follow-up time was 29 months (15-87 months). No recurrence, distant metastasis, or diseaserelated death occurred during follow-up.

\section{Discussion}

Neurofibroma is a neurogenic tumor that can occur everywhere in the body. Histopathology shows that the tumor can incorporate Schwann cells, perineural cells, fibroblasts cells, and collagen tissue. ${ }^{2,25,26}$ Multiple neurofibromas are closely related to neurofibromatosis (NF), an autosomal dominant hereditary disease, first named by Recklinghausen in 1882. NF is divided into two categories, NF type 1 and 2. NF type 1 is also called peripheral $\mathrm{NF}$, accounting for about $90 \%$ of NF cases. NF type 2 , known as bilateral acoustic NF, is relatively rare. ${ }^{4}$ In patients with NF, $10-25 \%$ of them were reported to have gastrointestinal-related discomfort, and less than 5\% have clinical symptoms. The small intestine is most often involved, followed by the stomach. ${ }^{27-30}$

To date, we have not found any reports on the incidence of solitary GN in previous studies. Our study showed GN accounted for $1.4 \%$ of gastric submucosal tumors. As we know, the common pathological types of Gastric submucosal tumors are stromal tumors, leiomyoma, lipoma, neuroendocrine tumors, calcified fibroma, hemangioma, etc, ${ }^{31}$ among which GN is extremely rare. The National Comprehensive Cancer Network guidelines recommend that lesions $>2 \mathrm{~cm}$ or smaller lesions with high-risk features such as irregular borders, cystic spaces, ulceration, echogenic foci, heterogeneity undergo resection. ${ }^{32}$ However, different lesion type, size, location, benign and malignant level, the treatment will be also different. ${ }^{33}$ In the present study, 6 out of 11 resected gastric submucosal tumors were $<20 \mathrm{~mm}$ in diameter, this was because the patients were too nervous and worried about a bad change in the lesion that they preferred a removal as soon as possible.

Eight previous studies of solitary GNs are summarized in Table 2. The average age of the eight patients was 55.0 \pm 11.2 years, ranging from 41 to 72 years and similar to our findings. $62.5 \%$ of the eight patients were male, while most of our patients were female. One patient with a family history of NF is more likely to suffer NF because GN may appear as the first symptom. Four patients with gastrointestinal diseases, which may have an impact on the occurrence of solitary GN because Stahn et al reported that solitary neurofibroma was associated with long-term chronic stimulation such as trauma, chronic inflammation, ischemia, or granuloma. ${ }^{34}$ Gastrointestinal solitary neurofibroma has no specific clinical symptoms. Patients' clinical symptoms mainly included abdominal pain $(50.0 \%)$ and epigastric discomfort $(25.0 \%)$ in Table 2 . The proportion was roughly agree with ours. Solitary GN had been reported in esophagogastric junction, ${ }^{35}$ the greater curvature of the stomach, ${ }^{1}$ pylorus, ${ }^{25}$ posterior wall of the upper gastric corpus, ${ }^{36}$ and anterior wall of the stomach. ${ }^{37}$ Our results showed most GNs occurred in the lower and middle parts of the stomach. 


\begin{tabular}{|c|c|c|c|c|c|c|c|}
\hline$\frac{\overline{\bar{g}}}{\mathrm{o}}$ & 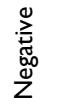 & 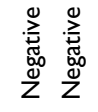 & 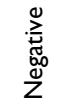 & $\Sigma$ & 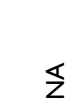 & & $\mathbb{Z} \Sigma$ \\
\hline$\frac{8}{\dot{n}}$ & $\begin{array}{l}\sum_{\bar{z}}^{0} \\
: \bar{y} \\
0\end{array}$ & 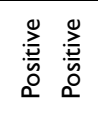 & $\begin{array}{l}\sum_{\bar{z}}^{0} \\
0 \\
0\end{array}$ & $\begin{array}{l}\sum_{\bar{z}}^{0} \\
\text { D. } \\
0\end{array}$ & $\sum_{\substack{\bar{y} \\
0}}^{0}$ & & $\sum_{\bar{z}}^{0} \mathbb{z}$ \\
\hline \multirow{2}{*}{ 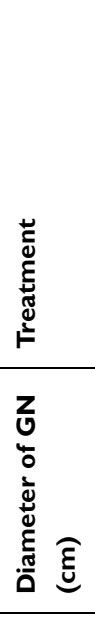 } & 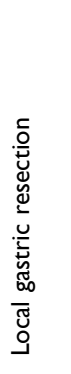 & \multicolumn{2}{|c|}{ 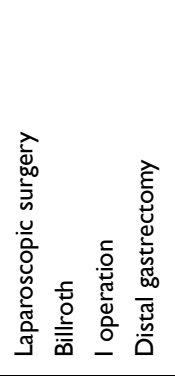 } & \multicolumn{2}{|c|}{ 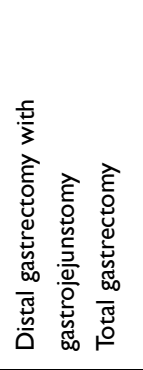 } & \multicolumn{2}{|r|}{ 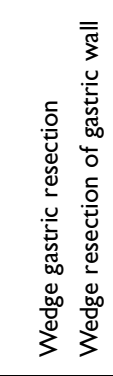 } \\
\hline & $\stackrel{\leftrightarrow}{+}$ & $\stackrel{\text { Ln }}{n} \stackrel{\circ}{\circ}$ & $\stackrel{\circ}{-}$ & 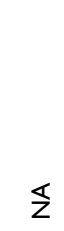 & $\Sigma$ & $\frac{5}{2}$ & 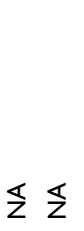 \\
\hline & 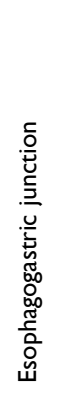 & 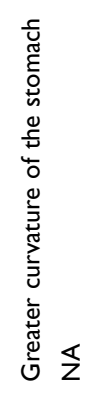 & $\begin{array}{l}\frac{n}{2} \\
\frac{0}{2} \\
0\end{array}$ & $\S$ & & 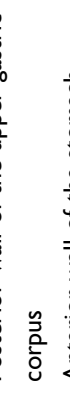 & 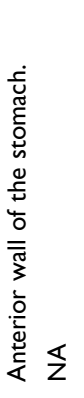 \\
\hline 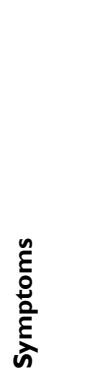 & 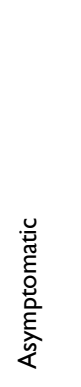 & 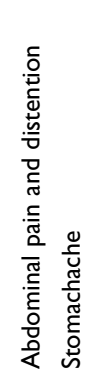 & 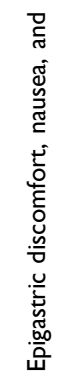 & 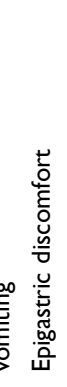 & 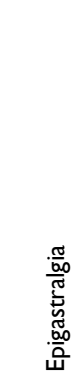 & 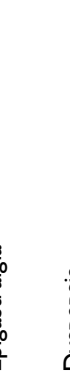 & 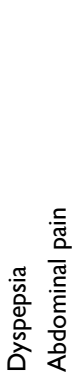 \\
\hline ๑̊ & $\frac{\frac{\omega}{\varrho}}{\Sigma}$ & 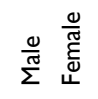 & $\frac{\frac{\omega}{\tilde{\omega}}}{\Sigma}$ & $\begin{array}{l}\frac{0}{\tilde{\varpi}} \\
\frac{\tilde{w}}{\Psi} \\
\end{array}$ & $\frac{\frac{0}{\pi}}{\Sigma}$ & 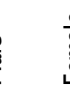 & 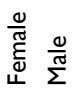 \\
\hline$\stackrel{\mathrm{g}}{<}$ & $\bar{n}$ & $\stackrel{\infty}{\bar{\sigma}}$ & $\stackrel{\infty}{\curvearrowleft}$ & $N$ & $\bar{\sigma}$ & & $\bar{\sigma} \stackrel{\infty}{\circ}$ \\
\hline હ্ঠ & $\stackrel{n}{2}$ & $\stackrel{+}{\circ} \stackrel{+}{\grave{c}}$ & $\frac{\pi}{\grave{N}}$ & $\frac{m}{i}$ & ڤ્ণ & & ○્ \\
\hline 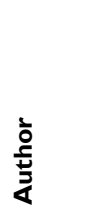 & 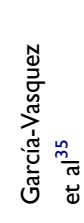 & 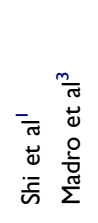 & 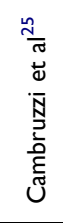 & 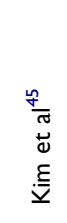 & 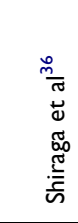 & 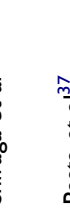 & 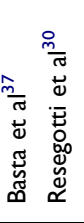 \\
\hline נ̆ & - & $N m$ & 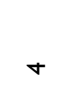 & in & 0 & & $\wedge \infty$ \\
\hline
\end{tabular}

Our study showed that benign GNs appeared as a homogeneous low-density mass during the plain and enhanced CT scan, which was consistent with the previous description. ${ }^{38}$ Another study reported that the density of malignant GNs was not uniform on the plain CT scan, with irregular low-density foci such as necrosis, hemorrhage, cystic changes and the GN may show irregular and uneven enhancement on the enhanced CT scan. ${ }^{39}$ We recommend patients have an MRI, because different signals also help to identify whether the tumor is benign or malignant. At the same time, we also recommend that patients have routine abdominal X-rays and ultrasound examinations to exclude the involvement of other parts of the digestive tract.

Pathological examination is the gold standard for the diagnosis of GN, among which S-100, NSE, and SOX-10 protein are the most specific. S-100 is a highly acidic calcium-binding protein, mainly distributed in glial and Schwann cells, and is involved in the proliferation, apoptosis, and differentiation of nerve cells. ${ }^{40}$ The expression of S-100 protein will increase when GN occurs. As summarized in Table 2, S-100 protein was positive in all cases except for one case with not available data. The S-100 protein in 11 patients in the present study was all positive, which was consistent with the findings in Table 2. It is worth noting that the S-100 protein can help identify only whether or not the lesion is neurogenic but cannot identify benign and malignant lesions. NSE is an isoenzyme specifically secreted by central neurons and neuroendocrine cells, which participates in the metabolic processes of nerve cells and maintains the normal physiological function of the nervous system. NSE is positive in solitary GN as reported by Madro et al. ${ }^{3}$ Of the patients, $45.5 \%$ were positive for NSE in our study, which further confirmed that the lesion was neurogenic. Positive NSE, S-100 protein, cannot predict prognosis. SOX-10 is a transcription factor involved in the survival, proliferation and differentiation of various cells in the nervous system. ${ }^{41}$ SOX-10 is expressed in Schwann cells and melanocyte lineages and is crucial for their development. Based on this, SOX-10 has been used as a new marker to diagnose tumors originating from these cells. ${ }^{42}$ Over the past few years, there has been growing evidence that SOX-10 is positive in many tumors of the central and peripheral nervous system. ${ }^{43}$ Only one patient was tested for SOX-10 in our study, and it was proved to be positive. In addition, positive or negative expression of CD117, CD34, SMA, Vim, Des, and Ki-67 can help identify GN 
and gastric stromal tumors, leiomyoma, leiomyosarcoma, etc.

GN is mostly benign, but there is a certain rate of malignant transformation, about $15.0 \%$; the probability of malignant transformation is higher especially in patients over 40 years old. ${ }^{44}$ Although there is no large sample survey on the prognosis and recurrence of GN, most researchers believe that GN with a clear diagnosis should be resected as soon as possible because of its malignant potential. Surgical modalities for solitary GN reported include open surgery, laparoscopic surgery, and endoscopic treatment. Shi et al recommended endoscopic resection as the preferred treatment for solitary GN because it is minimally invasive and can completely remove the lesion. ${ }^{1}$ Among the 11 patients undergoing endoscopic treatment, six patients underwent ESE procedures and five patients underwent EFTR procedures. All lesions were completely resected, with no postoperative adverse events. The median time of endoscopic resection was 80 minutes and the shortest time was only 14 minutes in our study. However, the operation time of open surgery to resect the solitary GN reported by Kim et al was 3 hours and 40 minutes. Notably, the longest operation time in our study was 170 minutes. We analyzed the possible reasons for this long operation time as follows: (I) The lesion originated from the deep muscularis propria, with a diameter of $3.5 \mathrm{~cm}$, which had the largest diameter among the 11 lesions. (II) The tumor mainly occurred outside the gastric cavity, which increased the difficulty of endoscopic operation. Therefore, we conclude that the time of endoscopic operation was closely related to the location, depth, size, and growth pattern of the lesion. We also propose that the lesion diameter of $3.5 \mathrm{~cm}$ may be a preliminary indicator to determine whether the tumor can be removed under endoscopy or not.

During the median follow-up of 29 months, all patients were in good condition, without recurrence or distant metastasis. Therefore, we recommend endoscopic treatment as the first choice for solitary GN, and specific endoscopic resection methods can be selected according to the origin of the lesion.

We reported 11 cases of solitary GN, all of which were successfully removed by ESE and EFTR procedures, suggesting that these are feasible, safe, and effective for the treatment of solitary GN. To our knowledge, this is the largest case series on ESE and EFTR for treatment of solitary GN.
The present study has several limitations. First, this was a retrospective study conducted in a tertiary hospital with only 11 patients enrolled because of the rarity of the lesion. Second, no comparison was made between surgical operations and ESE and EFTR procedures for solitary GN. Third, 3 of 11 patients were followed up for less than 24 months, which is relatively short, to evaluate the efficacy of endoscopic treatment for solitary GN.

\section{Conclusions}

EFTR and ESE can serve as feasible, safe, and effective treatments for solitary GN.

\section{Acknowledgments}

The authors appreciate the patients for their support. The authors thank the Ethics Committee of the Second Xiangya Hospital of Central South University for approving this study. This work was supported by the Key Research Project of Hunan Province (Grant number 2018SK21311). The authors thank editors and reviewers for valuable comments and suggestions for improving this manuscript.

\section{Disclosure}

The authors report no conflicts of interest in this work.

\section{References}

1. Shi L, Liu FJ, Jia QH, Guan H, Lu ZJ. Solitary plexiform neurofibroma of the stomach: a case report. World $J$ Gastroenterol. 2014;20:5153-5156. doi:10.3748/wjg.v20.i17.5153

2. Basourakos SP, Kasabwala K, Silich R, Mosquera JM, Choi B. Neurofibroma originating from a urachal mass. Can $J$ Urol. 2020;27:10407-10410.

3. Madro A, Kosikowski W, Drabko J, et al. Neurofibroma of the stomach without Recklinghausen's disease: a case report. Prz Gastroenterol. 2014;9:310-312. doi:10.5114/pg.2014.46168

4. Zwane NP, Noffke CE, Raubenheimer EJ. Solitary oral plexiform neurofibroma: review of literature and report of a case. Oral Oncol. 2011;47:449-451. doi:10.1016/j.oraloncology.2011.04.005

5. Behrad S, Sohanian S, Ghanbarzadegan A. Solitary intraosseous neurofibroma of the mandible: report of an extremely rare histopathologic feature. Indian J Pathol Microbiol. 2020;63:276-278. doi:10.4103/ IJPM.IJPM_28_19

6. Maheshwari V, Varshney M, Alam K, et al. Neurofibroma of parotid. BMJ Case Rep. 2011;2011(jul27 1):bcr0520114172-bcr0520114172. doi:10.1136/bcr.05.2011.4172

7. Garaffa G, Bettocchi C, Christopher N, Ralph D. Plexiform neurofibroma of the penis associated with erectile dysfunction due to arterial steeling. J Sex Med. 2008;5:234-236. doi:10.1111/j.17436109.2007.00629.x

8. Milathianakis KN, Karamanolakis DK, Mpogdanos IM, TrihiaSpyrou EI. Solitary neurofibroma of the spermatic cord. Urol Int. 2004;72:271-274. doi:10.1159/000077130

9. He Y, Wang J, Zhang Z, Yang H, Fu H. Solitary neurofibroma arising from the infratemporal fossa in a child. J Pediatr Surg. 2011;46:E1316. doi:10.1016/j.jpedsurg.2011.03.009 
10. Barajas-Gamboa JS, Florez-Salamanca L. Solitary neurofibroma in the abdominal wall of a patient without neurofibromatosis: case report. Biomedica. 2009;29:501-505. doi:10.7705/biomedica. v29i4.123

11. Namikawa T, Kawanishi Y, Fujieda Y, et al. Neurofibroma of the gallbladder not associated with neurofibromatosis. Surg Technol Int. 2016;30:89-92.

12. De Rosa A, Gomez D, Zaitoun AM, Cameron IC. Neurofibroma of the bile duct: a rare cause of obstructive jaundice. Ann R Coll Surg Engl. 2013;95:e38-40. doi:10.1308/003588413X13511609955931

13. Booka E, Kitano M, Nakano Y, et al. Life-threatening giant esophageal neurofibroma with severe tracheal stenosis: a case report. Surg Case Rep. 2018;4:107. doi:10.1186/s40792-018-0517-1

14. Panteris V, Vassilakaki T, Vaitsis N, et al. Solitary colonic neurofibroma in a patient with transient segmental colitis: case report. World J Gastroenterol. 2005;11:5573-5576. doi:10.3748/wjg.v11.i35.5573

15. Guo Y, Jing X, Zhang J, et al. Endoscopic removal of gastrointestinal stromal tumors in the stomach: a single-center experience. Gastroenterol Res Pract. 2019;2019:3087298. doi:10.1155/2019/ 3087298

16. Li DM, Ren LL, Jiang YP. Long-term outcomes of endoscopic resection for gastric subepithelial tumors. Surg Laparosc Endosc Percutan Tech. 2020;30:187-191. doi:10.1097/sle.0000000000000755

17. Zhai YQ, Chai N-L, Li H-K, et al. Endoscopic submucosal excavation and endoscopic full-thickness resection for gastric schwannoma: five-year experience from a large tertiary center in China. Surg Endosc. 2020;34:4943-4949. doi:10.1007/s00464-019-07285-w

18. Albrecht H, Raithel M, Braun A, et al. Endoscopic full-thickness resection (EFTR) in the lower gastrointestinal tract. Tech Coloproctol. 2019;23:957-963. doi:10.1007/s10151-019-02043-5

19. Chen Y, Wang M, Zhao L, et al. The retrospective comparison between submucosal tunneling endoscopic resection and endoscopic submucosal excavation for managing esophageal submucosal tumors originating from the muscularis propria layer. Surg Endosc. 2020;34:417-428. doi:10.1007/s00464-019-06785-Z

20. Liu J, Tan Y, Liu D, et al. Factors predicting technical difficulties during endoscopic submucosal excavation for gastric submucosal tumor. J Int Med Res. 2021;49:3000605211029808. doi:10.1177/ 03000605211029808

21. Jian G, Tan L, Wang H, et al. Factors that predict the technical difficulty during endoscopic full-thickness resection of a gastric submucosal tumor. Rev Esp Enferm Dig. 2021;113:35-40. doi:10.17235/ reed.2020.7040/2020

22. Tan Y, Tang X, Guo T, et al. Comparison between submucosal tunneling endoscopic resection and endoscopic full-thickness resection for gastric stromal tumors originating from the muscularis propria layer. Surg Endosc. 2017;31:3376-3382. doi:10.1007/s00464016-5350-7

23. Kim JW, Kim HS, Park DH, et al. Risk factors for delayed postendoscopic mucosal resection hemorrhage in patients with gastric tumor. Eur J Gastroenterol Hepatol. 2007;19:409-415. doi:10.1097/ MEG.0b013e32801015be

24. Nam HS, Choi CW, Kim SJ, et al. Risk factors for delayed bleeding by onset time after endoscopic submucosal dissection for gastric neoplasm. Sci Rep. 2019;9:2674. doi:10.1038/s41598-019-39381-1

25. Cambruzzi E, Pêgas KL, Azeredo A, Bombassaro I. Solitary plexiform neurofibroma determining pyloric obstruction: a case report. $J$ Bras Patol Med Lab. 2014;50:238-241. doi:10.5935/16762444.20140022

26. Nishikawa K, Omura N, Yuda M, et al. Video-assisted thoracoscopic surgery for localized neurofibroma of the esophagus: case report and review of the literature. Int Surg. 2013;98:461-465. doi:10.9738/ INTSURG-D-12-00021.1

27. Gogus S, Sarikayalar F, Akcoren Z, Yalnizoglu D, Hicsonmez A. Intestinal involvement and vasculopathy in von Recklinghausen's neurofibromatosis. Turk J Pediatr. 1997;39:117-122.
28. Huson SM, Harper PS, Compston DA. Von Recklinghausen neurofibromatosis. A clinical and population study in south-east Wales. Brain. 1988;111(Pt 6):1355-1381. doi:10.1093/brain/111.6.1355

29. Ventura A, Murinello A, Ribeiro J, Morgado A, Mota JA. [Von Recklinghausen's neurofibromatosis]. Acta Med Port. 1989;2:163-166. Swedish.

30. Resegotti A, Lasagna B, Garabello D, Papotti M. [Isolated neurofibroma of the stomach. Case report and review of the literature]. Minerva Chir. 1992;47:1501-1504. Romanian.

31. Nishida T, Kawai N, Yamaguchi S, Nishida Y. Submucosal tumors: comprehensive guide for the diagnosis and therapy of gastrointestinal submucosal tumors. Dig Endosc. 2013;25:479-489. doi:10.1111/ den. 12149

32. von Mehren M, Randall RL, Benjamin RS, et al. Soft tissue sarcoma, Version 2.2016, NCCN Clinical Practice Guidelines in Oncology. $J$ Natl Compr Canc Netw. 2016;14:758-786. doi:10.6004/ jnccn.2016.0078

33. Faulx AL, Kothari S, Acosta RD, et al. The role of endoscopy in subepithelial lesions of the GI tract. Gastrointest Endosc. 2017;85:1117-1132. doi:10.1016/j.gie.2017.02.022

34. Stahn V, Nagel I, Fischer-Huchzermeyer S, et al. Molecular analysis of hybrid neurofibroma/schwannoma identifies common monosomy 22 and alpha-T-Catenin/CTNNA3 as a novel candidate tumor suppressor. Am J Pathol. 2016;186:3285-3296. doi:10.1016/j. ajpath.2016.08.019

35. García-Vasquez C, Castellón-Pavon C, De-mingo M, et al. Sporadic neurofibroma on the esophagogastric junction. A case report. Revista espanola de enfermedades dig. 2015;107:324-325.

36. Shiraga N, Higuchi M, Hasebe T, et al. Sporadic gastric neurofibroma underneath early cancer: MDCT gastrography and histological findings. Radiat Med. 2007;25:236-239. doi:10.1007/s11604-0070122-x

37. Basta P, Sznajd J, Wachol D. [Gastric neurofibroma-still a diagnostic problem]. Przegl Lek. 2000;57:678-679. Polish.

38. Hirata K, Kitahara K, Momosaka Y, et al. Diffuse ganglioneuromatosis with plexiform neurofibromas limited to the gastrointestinal tract involving a large segment of small intestine. $J$ Gastroenterol. 1996;31:263-267. doi:10.1007/BF02389528

39. Coleman BG, Arger PH, Dalinka MK, et al. CT of sarcomatous degeneration in neurofibromatosis. AJR Am $J$ Roentgenol. 1983;140:383-387. doi:10.2214/ajr.140.2.383

40. Di Stefano A, Alcantarini C, Atzori C, et al. Cerebrospinal fluid biomarkers in patients with central nervous system infections: a retrospective study. CNS Spectr. 2020;25:402-408. doi:10.1017/ S1092852919000981

41. Cronin JC, Loftus SK, Baxter LL, et al. Identification and functional analysis of SOX10 phosphorylation sites in melanoma. PLoS One. 2018;13:e0190834. doi:10.1371/journal.pone.0190834

42. Miettinen M, McCue PA, Sarlomo-Rikala M, et al. Sox10-a marker for not only schwannian and melanocytic neoplasms but also myoepithelial cell tumors of soft tissue: a systematic analysis of 5134 tumors. Am J Surg Pathol. 2015;39:826-835. doi:10.1097/ PAS.0000000000000398

43. Karamchandani JR, Nielsen TO, van de Rijn M, West RB. Sox10 and $\mathrm{S} 100$ in the diagnosis of soft-tissue neoplasms. Appl Immunohistochem Mol Morphol. 2012;20:445-450. doi:10.1097/ PAI.0b013e318244ff4b

44. Levy D, Khatib R. Intestinal neurofibromatosis with malignant degeneration: report of a case. Dis Colon Rectum. 1960;3 (2):140-144. doi:10.1007/BF02616545

45. Kim S, Kim YS, Kim JH, Min YD, Hong R. Early gastric cancer with neurofibroma mimicking a metastatic node: a case report. $J$ Gastric Cancer. 2013;13:185-187. doi:10.5230/jgc.2013.13.3.185 


\section{Publish your work in this journal}

The International Journal of General Medicine is an international, peer-reviewed open-access journal that focuses on general and internal medicine, pathogenesis, epidemiology, diagnosis, monitoring and treatment protocols. The journal is characterized by the rapid reporting of reviews, original research and clinical studies across all disease areas. The manuscript management system is completely online and includes a very quick and fair peer-review system, which is all easy to use. Visit http://www.dovepress.com/ testimonials.php to read real quotes from published authors.

Submit your manuscript here: https://www.dovepress.com/international-journal-of-general-medicine-journal 